\title{
Addressing Child Stunting in Cameroon: The Imperative Need to Adopt an Equity-Focused Approach and Scale Up Key Nutrition Interventions Through Various Platforms
}

\author{
Roger Sodjinou ${ }^{1 *}$, Ismael Ngnie-Teta ${ }^{2}$, Arsene Azandossessi ${ }^{1}$ and Noel Marie Zagre ${ }^{3}$ \\ ${ }^{1}$ UNICEF Country Office, Yaounde, Cameroon \\ ${ }^{2}$ Helen Keller International, Yaounde, Cameroon \\ ${ }^{3}$ UNICEF Regional Office for West and Central Africa, Dakar, Senegal \\ *Corresponding Author: Roger Sodjinou, UNICEF Country Office, Yaounde, Cameroon.
}

Received: September 11, 2019; Published: October 09, 2019

DOI: 10.31080/ASNH.2019.03.0483

\section{Abstract}

There is paucity of information on how socio-economic factors influence the incidence of stunting in Cameroon. This study was undertaken to depict trends and determinants in inequities in child stunting and explore how socio-economic inequalities interfere with stunting in the country.

Data from nationally representative surveys available for the public were used to assess trends in stunting and its key drivers over a 25-year period. Data were derived from the Cameroon's Demographic and Health Surveys 1991, 1998, 2004 and 2011 and the 2014 Multiple Indicators Cluster Survey (MICS).

Over the last two decades, there has been a $40 \%$ increase in the number of stunted children. The burden of stunting is heterogeneous across regions, with the poorest regions being the most affected. Even though Cameroon has the largest share of GDP in the CEMAC zone, this has not trickled down enough to the poor and translated into a better nutrition situation of its population. Across the continuum of care, very few mothers and children are utilizing key nutrition interventions. For example, the proportion of children put to breast within the first hour after delivery is just 31\%. Likewise, only $28 \%$ of infants below 6 months of age are exclusively breastfed. Complementary feeding practices are also sub-optimal, with only $16.6 \%$ of children receiving a minimum acceptable diet and only 33\% receiving food from four or more food groups. Food insecurity, poor access to health and sanitation services, as well as poor maternal health are hindering Cameroon from making progress towards reducing child stunting.

There is an urgent need to address stunting in Cameroon, using a deliberate equity driven approach to reduce disparities. A multisectoral approach addressing key drivers of malnutrition, while focusing on the first 1000 days window of opportunity, would be more appropriate.

Keywords: Malnutrition; Poverty; Diet; Economic Growth; Central Africa

\section{Introduction}

Cameroon is a lower-middle-income country located in Central Africa. It has a population of about 24 million [1]. Over the last two decades, the country has made impressive macroeconomic progress. The Gross National Income per capita has doubled from
$\$ 680$ to $\$ 1,370$ between 2000 and 2017. Likewise, poverty headcount ratio at national poverty lines has slightly declined from $40 \%$ in 2000 to $37 \%$ in 2017 [2]. Despite a relatively low investment in social services, particularly in health where the government budget allocated to the sector has barely exceeded $5 \%$ over the last

Citation: Roger Sodjinou., et al. "Addressing Child Stunting in Cameroon: The Imperative Need to Adopt an Equity-Focused Approach and Scale Up Key Nutrition Interventions Through Various Platforms". Acta Scientific Nutritional Health 3.11 (2019): 19-27. 
decades, there have also been significant gains in health, education and other sectors [2]. For instance, under five mortalities have declined from 140 to 84 deaths per 1,000 live births between 1990 and 2017 [3]. In the same vein, the proportion of children aged 12 23 months immunized against measles has increased from 56\% to $77 \%$ between 1990 and 2018 [2]. Life expectancy at birth has also increased from 52 years to 58 years during the same period. In addition, birth attendance by skilled health staff rose from $58 \%$ to $65 \%$ between 1990 and 2017 [2]. In the education sector, there has been a significant improvement in the primary completion rate ( $51 \%$ in 2000 vs. $70 \%$ in 2017). Female secondary education enrolment rate has also increased from $28 \%$ to $46 \%$ between 2007 and 2012 [2].

These substantial gains in economic growth, health and education have not yet been translated into a tangible reduction in child malnutrition in Cameroon. Stunting is still high at 32\%. Child wasting is also above 5\% [4]. Likewise, underweight persistently remains above its level of 1991 (13.6\%) [4]. Micronutrient deficiencies are also important public health concerns [5]. Urbanization and changes in diet and lifestyle patterns are associated with a shift in the country's nutrition profile, with an emerging problem of overweight among children $(6.7 \%)$ alongside undernutrition [4].

The fact that one in three children continues to suffer from stunting in Cameroon is a matter of serious concern not only from a public health perspective but also from a long-term economic development standpoint. Child stunting is associated with increased morbidity and mortality, impaired physical growth, suboptimal cognitive development as well as increased risks of cardiometabolic diseases in adulthood. Moreover, stunting limits the learning potential in childhood and is associated with lower productivity and reduced earnings in adulthood. It also impedes socio-economic growth and national development [6-9]. Addressing stunting in Cameroon is therefore of paramount importance.

To date, there have been limited studies exploring the magnitude of stunting in Cameroon and its key drivers. The present paper attempts to contribute to filling this knowledge gap and highlights priority steps to be taken in addressing child stunting from an equity prospect in Cameroon.

\section{Materials and Methods}

Data

In this study, we used data from Cameroon's Demographic and Health Surveys 1991, 1998, 2004 and 2011. We also used data from the 2014 Multiple Indicators Cluster Survey (MICS). These are two nationally representative surveys designed to collect key health, nutrition and welfare indicators on households, children and their mothers. These data which are available for the public, were used to assess trends in stunting and its key drivers over a 25-year period.

\section{Study variables}

The main outcome indicator of interest for this study was the prevalence of stunting among children under five in Cameroon. Stunting was defined as the proportion of children aged 0 to 59 months whose height for age is below minus two standard deviations from the median of the WHO Child Growth Standards [10]. Wasting and underweight were defined as weight-for-height $\mathrm{z}$ score and weight-for-age z-score less than -2.0 standard deviations below the reference median respectively [10].

The key drivers of stunting in Cameroon were selected based on the results of previous studies and the UNICEF conceptual framework for malnutrition [11,12]. Table 1 describes the selected determinants of stunting and related variables.

\begin{tabular}{|c|c|c|}
\hline $\begin{array}{l}\text { Level of } \\
\text { analysis }\end{array}$ & Key variables & Description of the variables \\
\hline Outcome & $\begin{array}{c}\text { Trends in stunt- } \\
\text { ing }\end{array}$ & $\begin{array}{l}\text { Proportion of stunted children } \\
\text { Number of stunted children }\end{array}$ \\
\hline \multirow[t]{5}{*}{$\begin{array}{l}\text { Under- } \\
\text { lying } \\
\text { drivers }\end{array}$} & IYCF practices & $\begin{array}{l}\text { Early initiation of breastfeeding } \\
\text { Exclusive breastfeeding during the } \\
\text { first six months }\end{array}$ \\
\hline & $\begin{array}{l}\text { Access to water } \\
\text { and sanitation }\end{array}$ & $\begin{array}{l}\text { Open defecation } \\
\text { Access to improved water }\end{array}$ \\
\hline & $\begin{array}{l}\text { Access to health } \\
\text { services }\end{array}$ & $\begin{array}{l}\text { Access to ORS/Zinc to treat diar- } \\
\text { rhea } \\
\text { Use of bednet } \\
\text { Full immunization at one year of } \\
\text { age } \\
\text { Delivery in health facility }\end{array}$ \\
\hline & Maternal health & $\begin{array}{l}\text { Birth interval } \\
\text { Low birth weight } \\
\text { Antenatal consultations }\end{array}$ \\
\hline & Food insecurity & $\begin{array}{l}\text { Food insecurity by region } \\
\text { Household food insecurity }\end{array}$ \\
\hline $\begin{array}{l}\text { Basic } \\
\text { drivers }\end{array}$ & $\begin{array}{l}\text { Income, } \\
\text { poverty and } \\
\text { inequalities }\end{array}$ & $\begin{array}{l}\text { Wealth quintile } \\
\text { Sex, place of residence and } \\
\text { mother's education level } \\
\text { Share of regional GDP }\end{array}$ \\
\hline
\end{tabular}

Table 1: Study variables. 


\section{Results and Discussion}

Understanding the situation of stunting in Cameroon

Trends in malnutrition

Figure 1 shows trends in the prevalence rate of stunting, wasting and underweight in children under five. Between 1991 and 2011, stunting and wasting increased respectively from $24.4 \%$ to $32 \%$ and from 3 to $5.6 \%$. There has been a decline in Underweight since 1998 even though the rate persistently remains above its level of 1991 (13.6\%).

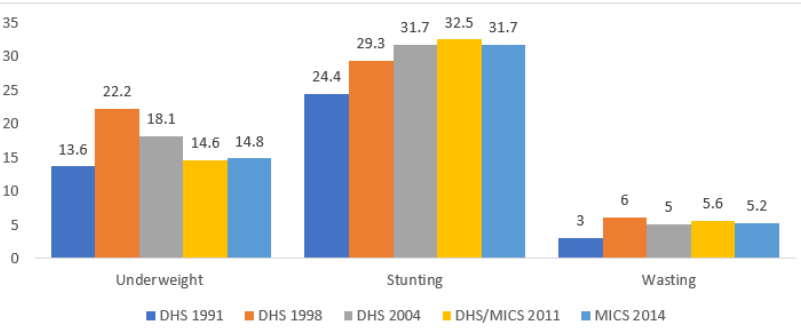

Figure 1: Trends in malnutrition in Cameroon (1991-2014).

Trends in stunting prevalence and burden

Between 1991 and 2014, there has been an increase in both the rate of stunting (24.4\% to $31.7 \%$ ) and the number of stunted children (840.000 to 1.170 .000 ) according to available data (Figure 2).

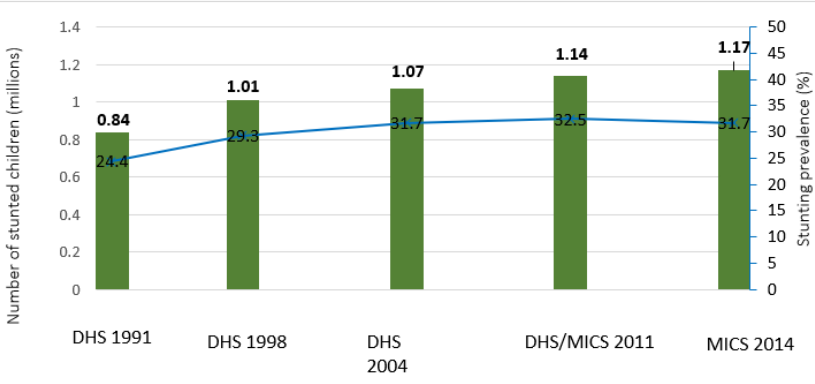

Figure 2: Trends in stunting prevalence and burden (1991-2014).

Prevalence of stunting and share of regional GDP

Cameroon is the wealthiest country of the Central Africa Economic and Monetary Community (CEMAC), made up of six countries (Cameroon, Central African Republic, Chad, Congo, Equato- rial Guinea and Gabon). It accounts for the largest share of GDP of the region at around $40 \%$ (Figure 3 ). Stunting is more prevalent in Cameroon than in other countries of the CEMAC region with lower economic level such as Equatorial Guinea (26.2\%), Congo (21.2\%) and Gabon (17.5\%). On the other hand, this rate (32\%) is lower than that of the two poorest countries of the CEMAC region, Chad and CAR (Figure 3).

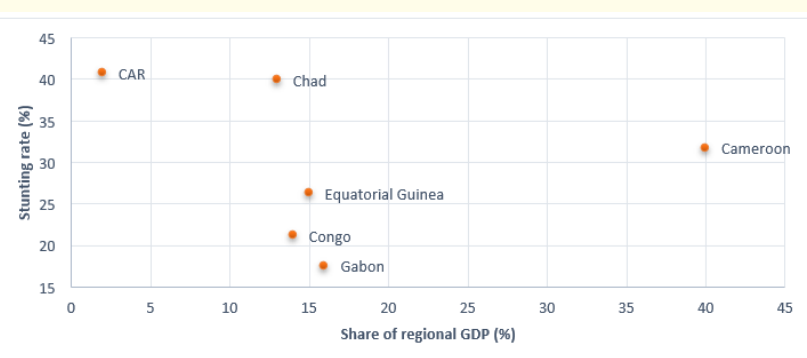

Figure 3: Prevalence of stunting and share of regional GDP.

\section{Stunting and poverty level}

At national level, stunting is more concentrated among poor people. Stunting rates have been consistently higher among poorer wealth quintiles in Cameroon since 2006 (Figure 4). However, inequalities have narrowed over time. In 2006, there was a difference of 35 percentage points in the stunting rate between the poorest quintile (50\%) and the richest (15\%) as opposed to 27 percentage points in 2014 due to a faster reduction of stunting rates among the poorest.

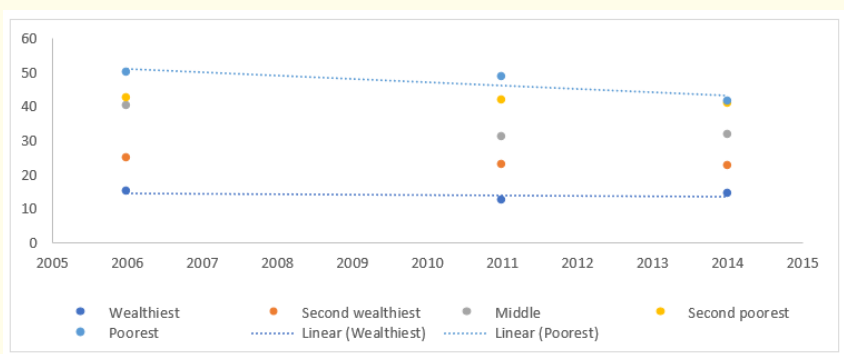

Figure 4: Stunting rates by wealth quintiles.

Geographical and socio-economic disparities in stunting

A similar pattern is observed when considering data at the subnational level. The latest available data indicate that stunting is 
more prevalent in regions with the largest share of people living on less than \$1.95 per day such as Far North, North, Adamawa and North West. The prevalence of stunting is above $30 \%$ in all these regions (Figure 5). The East region is also among the regions with the highest stunting rate.

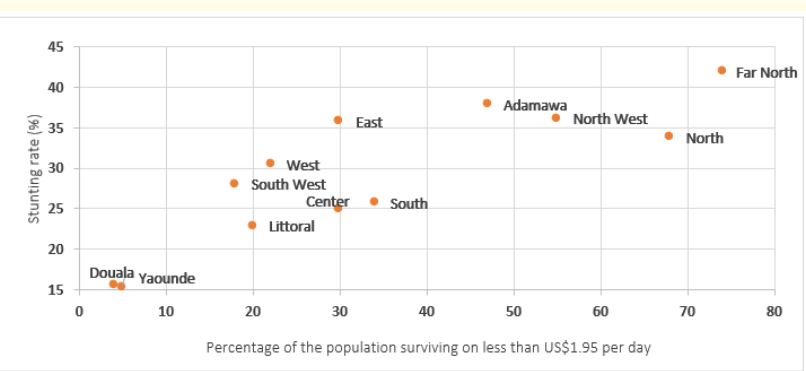

Figure 5: Stunting rates by region.

The nutrition situation of these hard-hit regions has not changed much over time (Figure 6). The latest available data indicate that stunting rates have even worsened in these hard-hit regions during the last decade, except the North region where there has been a substantial reduction although the rate is still high (33.8\%).

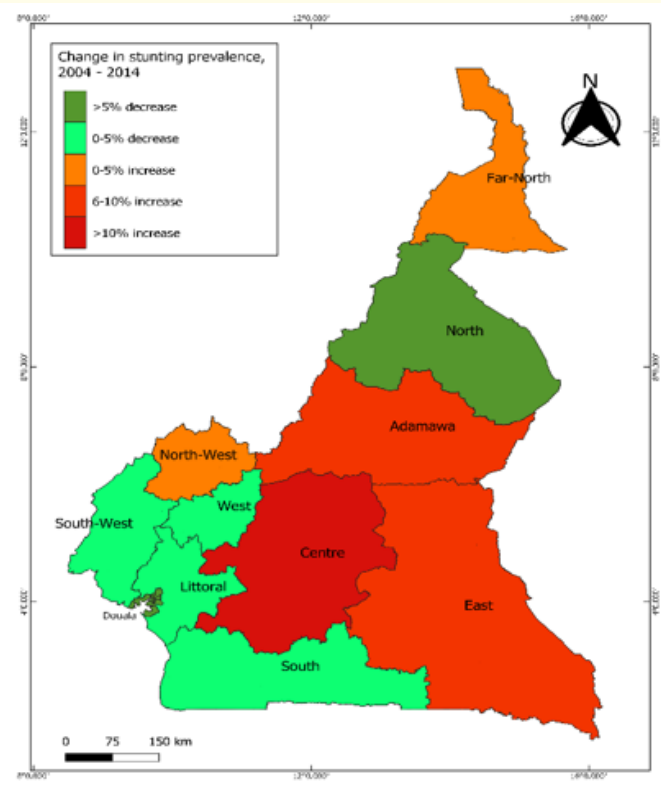

Figure 6: Change in stunting prevalence from 2004 to 2014.
Other inequities associated to stunting in Cameroon are related to sex, place of residence and mother's educational level. Available data shows that stunting rates have been consistently higher among boys than girls during the last decade (Figure 7). Likewise, children living in rural areas are most affected by stunting than those living in urban areas. Unlike wealth quintiles, the gap in inequity between the rural and urban areas has not decreased after 10 years. Moreover, children of mothers with low levels of education are more likely to be stunted (Figure 7).

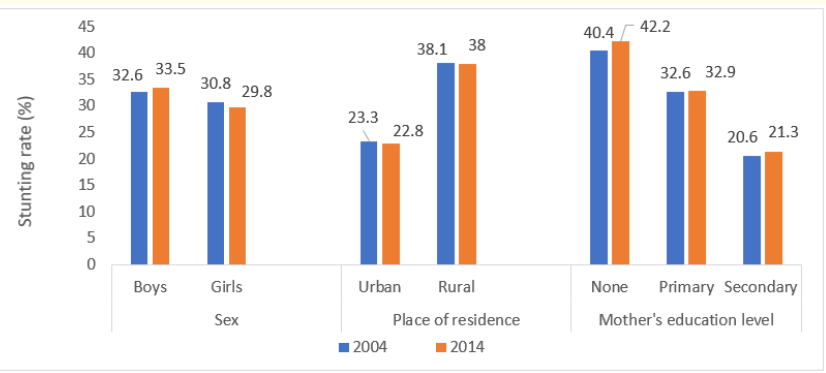

Figure 7: Inequities in stunting in Cameroon (2004-2014).

\section{Underlying determinants of stunting in Cameroon Trends in IYCF practices}

A review of the latest available data reveals that only few children in Cameroon are benefiting from improved feeding practices across the continuum of care (Figure 8). The proportion of children put to breast within the first hour after delivery is just $31 \%$. Likewise, only $28 \%$ of infants below 6 months of age are exclusively breastfed (Figure 8). Complementary feeding practices are also sub-optimal, with only $16.6 \%$ of children receiving a minimum acceptable diet and only $33 \%$ receiving food from four or more food groups.

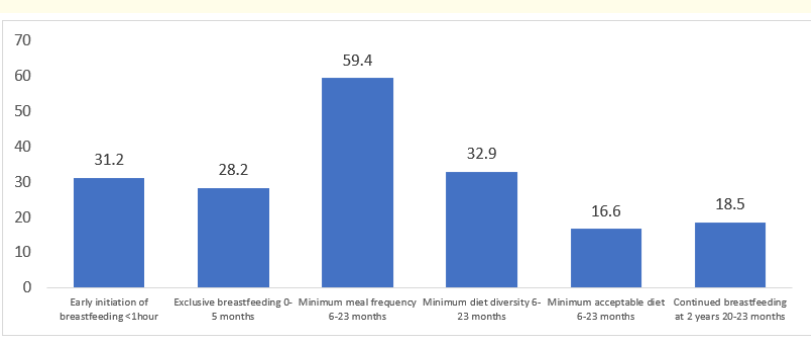

Figure 8: Key indicators related to IYCF. 
Early initiation of breastfeeding and exclusive breastfeeding rates during the first 6 months have only slightly improved during the last decade. These rates are still below the expected levels required to ensure growth in children in Cameroon (Figure 9).

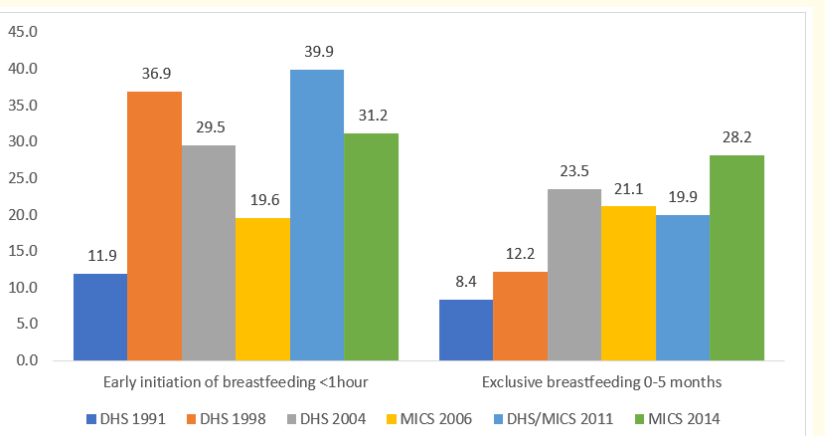

Figure 9: Trends in early initiation of breastfeeding and exclusive breastfeeding.

Rates of early initiation of breastfeeding have been persistently higher in urban areas than in rural areas since 1991 (Figure 10).

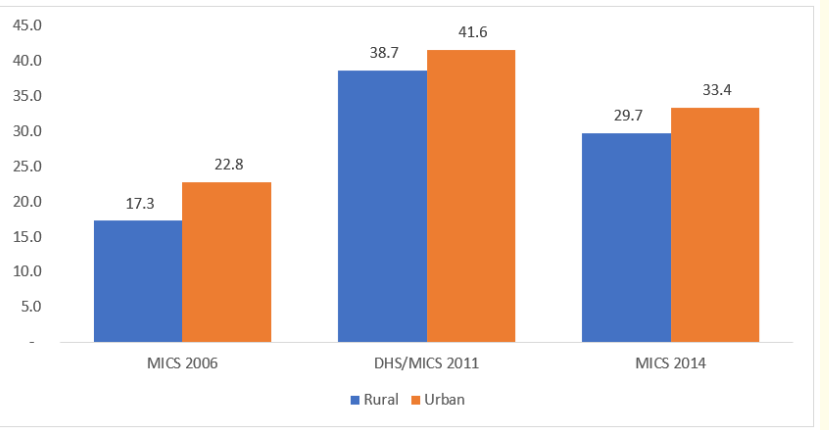

Figure 10: Early initiation of breastfeeding according to place of residence.

A similar trend is noted among wealth quintiles although inequalities have narrowed over time (Figure 11).

In addition, this rate is even low in regions with relatively low stunting rates such as South, Center, Douala and Yaounde (Figure 12).

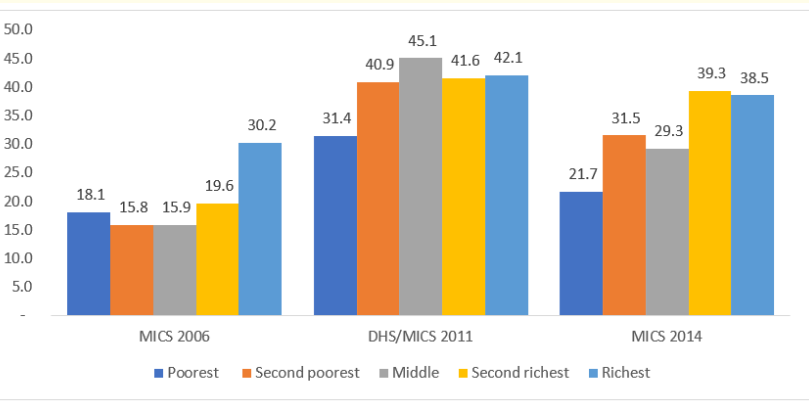

Figure 11: Early initiation of breastfeeding according to wealth quintiles.

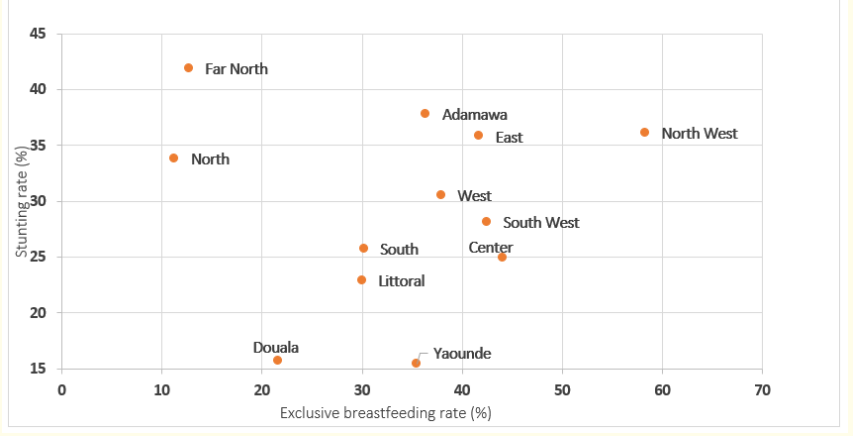

Figure 12: Stunting and exclusive breastfeeding rates in the different regions of Cameroon.

\section{Trends in access to improved water and sanitation}

There has been progress in providing access to improved water and ensuring adequate environmental sanitation in Cameroon between 1991 and 2014. The proportion of people that have access to improved water increased from $42 \%$ to $73 \%$ during this period. In the same vein, the practice of open defecation decreased from $7 \%$ to $5 \%$ during this period (Figure 13). There are however large variations among regions, with the least improvements in the poor regions which are home to the vast majority of people living in extreme poverty (Figure 13). 


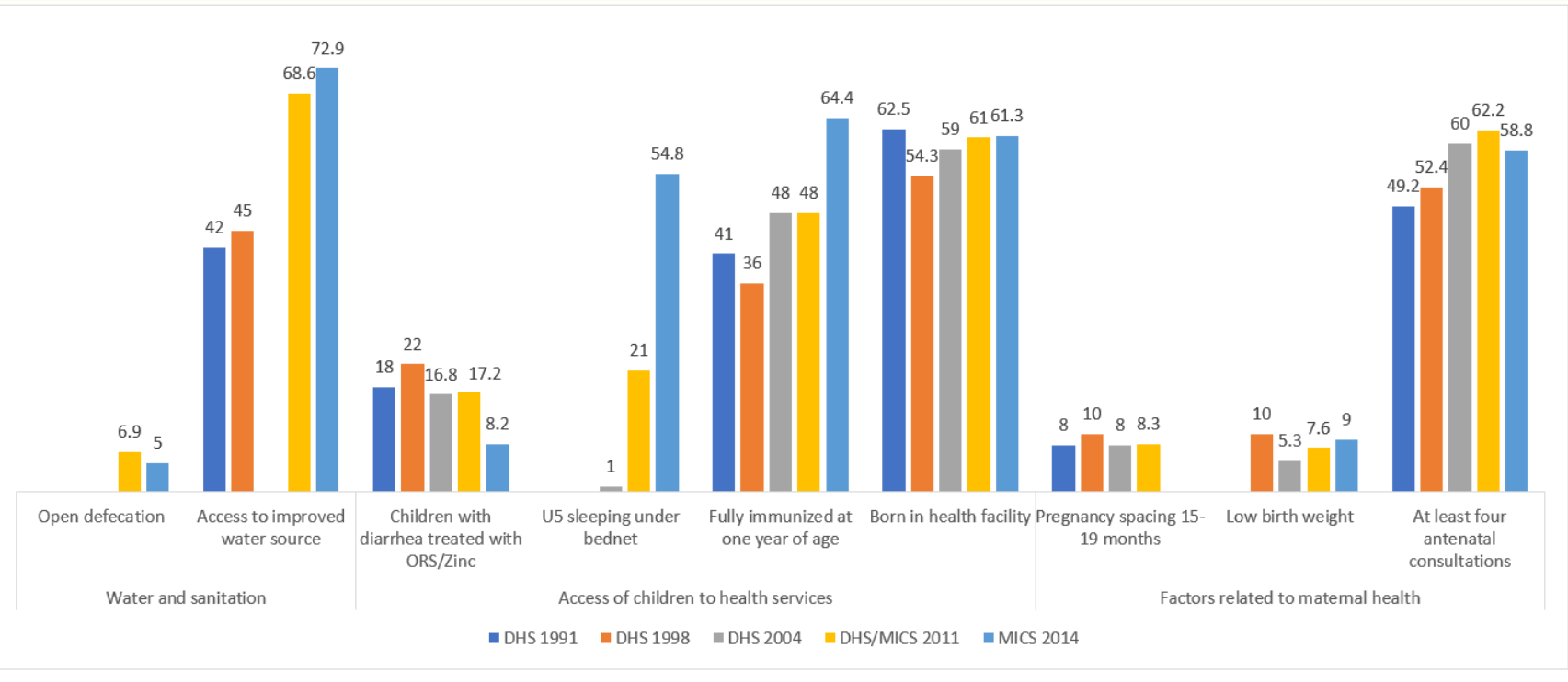

Figure 13: Trends in key environmental and health factors associated with stunting.

Trends in access to health services

Over the past two decades, there has been limited progress in access of children to health services. The proportion of children with diarrhea treated with ORS and zinc fell from $18 \%$ to $8 \%$ between 1991 and 2014 (Figure 13). Likewise, the proportion of children born in health facilities decreased slightly from $62.5 \%$ to $61.3 \%$ during the same period (Figure 13). There has been some progress in the access of children to immunization services and malaria prevention measures however more work needs to be done to achieve universal immunization coverage and at-scale use of bed nets among children.

There are also significant gaps and geographic variations in the access to immunization and malaria prevention measures (Figure 13). The poorest regions of the country (Far North, North, Adamawa and East) have also the highest under five mortality rates (Figure 14). The situation has not changed over the past two decades (data not shown).

\section{Trends in factors related to maternal health}

Between 1991 and 2014, there has been no or limited progress in adequate birth spacing (only $8 \%$ of women have adequate birth

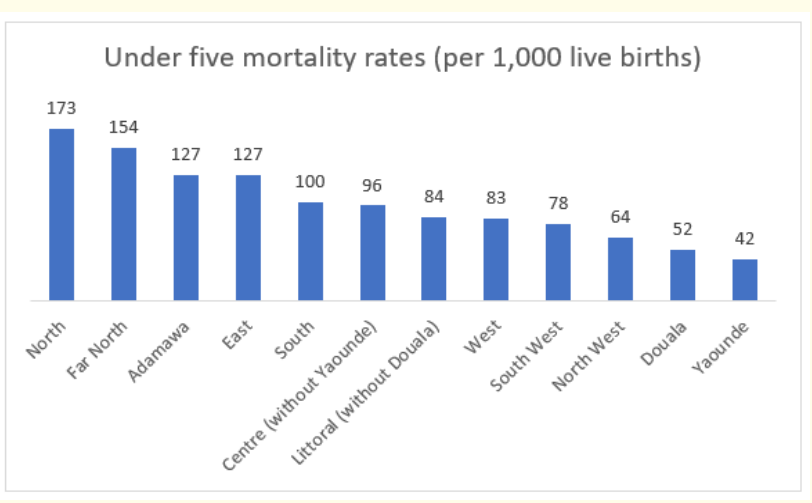

Figure 14: Under five mortality rates in the different regions of Cameroun (MICS 2014).

spacing) and attendance of at least four antenatal consultations during pregnancy (from $49 \%$ to 58\%). These indicators are still below the expected levels required to ensure optimal maternal and child health (Figure 12). In addition, the prevalence of low birth rate has remained almost at the same level since 1998 (Figure 13). 


\section{Trends in food security}

Food insecurity has always been a persistent problem in some parts of Cameroon. The latest data indicate that around $16 \%$ of household are food insecure in Cameroon (3.9 million people). The most affected regions (Far North, Adamawa, North, North West, and West) are also the ones with the highest stunting rates (Figure 15). Similar trends have been observed over the past two decades (data not shown).

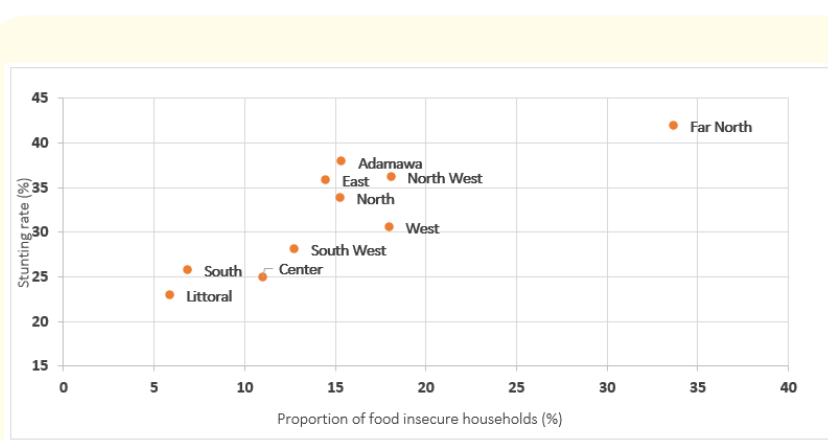

Figure 15: Stunting and household food insecurity in the different regions of Cameroon.

\section{Discussion}

In this study, we assessed the influence of geographical and socio-economic inequalities on the magnitude and trends in the prevalence of stunting in Cameroon.

Our results indicate that stunting is still a persistent problem in Cameroon, with a $40 \%$ increase in the number of stunted children over the last two decades. At the current pace, Cameroon is far from reaching the World Health Assembly targets of reducing by $40 \%$ the number of stunted children in the country by 2025 [6]. Substantial investments in nutrition program design, monitoring for results and management need to be made for this target to be reached.

Like in other countries in Africa [13,14] and Asia [15-18], we found marked disparities in stunting across the socio-economic spectrum in Cameroon. The burden of stunting is heterogeneous across the regions, with the poorest regions being the most affected. The fact that these regions are the most food insecure, with a vast majority of rural dwellers with low levels of education and have a low access to health, hygiene and sanitation services could partly explain this situation.
The fact that Cameroon is a low-middle income country, with the highest share of regional GDP in the CEMAC zone, has not translated in a better nutritional status of its population as opposed to other countries in the CEMAC region such as Congo, Equatorial Guinea and Gabon. This means that the effects of economic growth in Cameroon have not trickled down enough to the poor. There is an urgent need for redistribution of resources above the poverty level to improve maternal and child nutrition outcomes in Cameroon. Development partners in Cameroon should continue to join hands to engage high-level discussions with national authorities on the need to invest in social sectors to bridge the poverty gap in the country.

Our data show that across the continuum of care, very few mothers and children are utilizing key preventive and curative nutrition interventions to ensure optimal growth and development in children in Cameroon. Poor infant and young child feeding practices are still a major impediment to optimal child growth in Cameroon. The fact that these indicators are even suboptimal in the regions of Cameroon with the lowest stunting rates indicating the urgent need to put in place a country-wide framework that will enable the promotion and the protection of IYCF practices through a multisystem platform (health, social protection, education, agriculture, etc.), using both public health practitioners and community-based networks.

Our results also indicate that poor access to health, water and sanitation services is hindering Cameroon from making strides in reducing child stunting and other forms of malnutrition. The importance of ensuring access to ORS and zinc for an effective treatment of diarrhea cannot be overemphasized. Diarrhea is a condition, if left untreated, that can lead to malnutrition, which in turn increases the likelihood of having other childhood diseases [19]. Unfortunately, only a tiny proportion of children with diarrhea episodes are treated with ORS and Zinc in Cameroon. In addition, low immunization coverage and higher incidence of malaria, especially in endemic zones, are key drivers that could partly explain the higher incidence of malnutrition in Cameroon. Likewise, factors related to maternal health and status such as inadequate birth spacing, low utilization of antenatal care services, low maternal literacy and a relatively modest proportion of birth attended by skilled health professionals contribute to low utilization of effective nutrition services and poor nutrition outcomes in Cameroon. 
Overall, there is an urgent need to address stunting in Cameroon, using a deliberate equity driven approach to reduce disparities. Given that there a myriad of drivers at play, a multisectoral approach focusing on scaling up nutrition specific interventions and nutrition-sensitive approach would help accelerate progress towards reducing stunting in Cameroon. Moreover, these efforts should be grounded on a life-cycle approach while maximizing the impact of interventions during the critical first 1000 days [20].

\section{Conclusion}

Our results highlighted the persistence of stunting and its heterogenous distribution across geographical and socio-economic spectrum in Cameroon. They also indicate that across the continuum of care, very few children in Cameroon are benefiting from key services that would allow them to be free from malnutrition. Our data indicates the urgent need to adopt an equity-focused approach to nutrition programming in the country. They also underscore the need to accelerate progress towards reducing stunting and other forms of malnutrition by scaling up key effective nutrition interventions for children and their mothers. It is imperative to use a multisectoral approach addressing key drivers of malnutrition, while focusing on the first 1000 days window of opportunity.

\section{Acknowledgements}

We thank all the staff in the nutrition section of UNICEF Cameroon for their support and contribution. We are grateful to Felix Mpako for the assistance in the production of the figure 6 of the manuscript.

\section{Conflict of Interest}

The authors declare that they have no competing interests. The opinions and points of view expressed in this article are solely those of the authors and do not necessarily reflect the official positions or policies of their affiliated institutions.

\section{Bibliography}

1. http://worldpopulationreview.com/countries/cameroonpopulation/

2. http://data.worldbank.org/country/cameroon

3. https://data.uniceforg/country/cmr/

4. Institut National de la Statistique (INS). "Enquête à Indicateurs Multiples". ICF International. Maryland (2014): 489.
5. Engle-Stone R., et al. "Plasma ferritin and soluble transferrin receptor concentrations and body iron stores identify similar risk factors for iron deficiency but result in different estimates of the national prevalence of iron deficiency and iron-deficiency anemia among women and children in Cameroon". Journal of Nutrition 143.3 (2013): 369-377.

6. World Health Organization. "Global nutrition targets 2025: stunting policy brief". World Health Organization. Geneva (2014): 10.

7. Martorell R. "Undernutrition during pregnancy and early childhood: consequences for cognitive and behavioral development". Elsevier Science BV. Amsterdam and New York (1997): 39-83.

8. Dewey KG., et al. "Long-term consequences of stunting in early life". Maternal and Child Nutrition 7 (2011): 5-18.

9. Victora CG., et al. "Maternal and child undernutrition: consequences for adult health and human capital". The Lancet 371.9609 (2008): 340-357.

10. Kristen C., et al. "Guide to Anthropometry: A Practical Tool for Program Planners, Managers, and Implementers". Food and Nutrition Technical Assistance III Project (FANTA)/ FHI 360. Washington (2018): 231.

11. Bhutta ZA., et al. "Evidence-based interventions for improvement of maternal and child nutrition: What can be done and at what cost?". The Lancet 382.9890 (2013): 452-477.

12. Black RE., et al. "Maternal and child undernutrition and overweight in low-income and middle-income countries". The Lancet 382.9890 (2013): 427-451.

13. Jonah CMP., et al. "A comparative analysis of socioeconomic inequities in stunting: a case of three middle-income African countries". Archives of Public Health 10.76 (2018): 77.

14. Zere E., et al. "Inequities in under-five child malnutrition in South Africa". International Journal for Equity in Health 2.7 (2003): 1-10.

15. Aguayo VM., et al. "Determinants of child stunting in the Royal Kingdom of Bhutan: an in-depth analysis of nationally representative data". Maternal and Child Nutrition 11.3 (2015): 333345.

16. UNICEF. "Stop stunting in south Asia: a common narrative on maternal and child nutrition". UNICEF. Kathmandu (2015): 19. 
17. Krishna A., et al. "Trends in inequalities in child stunting in South Asia". Maternal and Child Nutrition 14. 4 (2018): e12517.

18. Angdembe MR., et al. "Trends and predictors of inequality in childhood stunting in Nepal from 1996 to 2016". International Journal for Equity in Health 18.1 (2019): 42.

19. Guerrant RL., et al. "Diarrhea as a cause and an effect of malnutrition: diarrhea prevents catch-up growth and malnutrition increases diarrhea frequency and duration". The American Journal of Tropical Medicine and Hygiene 47.1 (1999): 28-35.

20. Prentice AM., et al. "Critical windows for nutritional interventions against stunting". The American Journal of Clinical Nutrition 97.5 (2013): 911-918.

Volume 3 Issue 11 November 2019

(C) All rights are reserved by Roger Sodjinou., et al. 